\title{
A study of publication trajectories of the Brazilian Computer Science community
}

\author{
MARCELO K. ALBERTINI, ANDRÉ R. BACKES and ADRIANO L. DE SÁ \\ Faculdade de Computação, Universidade Federal de Uberlândia, Campus Santa Mônica, Av. \\ João Naves de Ávila, 2121, Santa Mônica, 38400-902 Uberlândia, MG, Brazil \\ Manuscript received on June 6, 2018; accepted for publication on September 17, 2018
}

\begin{abstract}
How to cite: ALBERTINI MK, BACKES AR AND SÁ AL. 2019. A study of publication trajectories of the Brazilian Computer Science community. An Acad Bras Cienc 91: e20180559. DOI 10.1590/0001-3765201920180559.
\end{abstract}

\begin{abstract}
The average faculty productivity have been described as a rapid rise-short peak-gradual decline pattern. Way et al. (2017) have studied this pattern for faculty careers in Computer Science in North America using a piecewise linear model. In this paper, we use a similar methodology and study trajectories $(N=20655)$ of the Brazilian Computer Science community. First, we have evaluated how the median publication count of researchers is related to institution prestige and public vs. private administration. Second, we have studied how the annual publication rates have increased and its variation according to prestige ranks of institutions. Third, we have found the average trajectory can indeed be described as the canonical rapid increase and slower decrease in productivity. For individual trajectories of senior researchers we have observed only $4.5 \%$ of trajectories are well explained by the conventional narrative of rapid rise and gradual decline model. We also have found polynomial models of degrees 1 to 3 explain almost $63.1 \%$ of trajectories. The rest of trajectories are considered unstable and not well explained by neither of approaches.
\end{abstract}

Key words: Plataforma Lattes, faculty productivity, publication count, Brazilian Computer Science community.

\section{INTRODUCTION}

There are three major foci on analysis of curriculum vitaes (Cañibano and Bozeman 2009) career trajectories, mobility and study of collective work. Bayer and Dutton (1977) have studied productivity trajectories as a function in time. Let $y$ represent productivity and $x$ be time. A researcher can keep a steady growing productivity as a function $y \sim x$; a function of declining rate of productivity $y \sim \log x$ ; a spurt function $y \sim x^{3}-x^{2}+x$ for a trajectory with a burst of productivity; or an obsolescence

Correspondence to: Marcelo Keese Albertini

E-mail: albertini@ufu.br

ORCid: https://orcid.org/0000-0002-1846-946X function with a burning-out phase of rapid decreasing $y \sim-x^{2}+x+a$.

Factors cited for productivity changes include seniority effects, cognitive decline with age, and formation of research teams (Levin and Stephan 1991, Fortunato et al. 2018). Recently Way et al. (2017) argued individual trajectories for Computer Science market in North America are better explained by a piecewise linear model composed of 2 linear functions than by a rapid-increase, shortpeak and gradual decrease, a conventional narrative described by an obsolescence function.

In comparison to North America, the Brazilian Computer Science community is underdeveloped. It has been less than 40 years since the first PhDs 
working in this field were granted their degrees (see Figure 2 below). Additionally, few studies on the career trajectory of Brazilian researchers can be found. Scarpelli et al. (2008) studied the profile of the Brazilian researchers in Dentistry which were granted scholarships as a recognition for their high productivity from the Brazilian National Research Council (CNPq). This study indicated that 90.3\% of the granted researchers developed their activities in public institutions and only $9.7 \%$ in private institutions. Most of them, 75.0\%, worked in the State of São Paulo. Researchers awarded with category 1 grants, which are of the highest prestige, were found to account for $53.5 \%$ of production, while researchers in category 2 accounted for $45.1 \%$ of production. Santos et al. (2012) also applied similar methodology to learn the distribution and imbalance of grants to researchers in a subfield of studies about oral pathologies. They have learned only three institutions (Universidade de São Paulo, Universidade Federal de Minas Gerais and Universidade de Campinas) concentrated almost half of higher productivity researchers. Picinin et al. (2016) analysed productivity grants in the context of production engineering field. They studied individual trajectory profiles of granted researchers and concluded that there is a logical coherence regarding distribution of grants.

Mendes et al. (2010) conducted studies to evaluate the productivity of scholars in the field of Medicine. The studies analyzed trajectories of 383 CNPq productivity grant researchers from 2005 to 2007. Such studies pointed out that among all researchers, $65.9 \%$ were male, $72.8 \%$ worked on 2 states of the 27 federative units in Brazil, and 97.1\% are employed in universities. The concentration of researchers in a few Brazilian States, namely São Paulo, Rio de Janeiro and Minas Gerais, is a wellknown fact (Mugnaini et al. 2004).

In 2000, Guimarães et al. (2010) found more than $70 \%$ of PhDs working in Brazil obtained their degrees in Brazilian institutions. In three fields, however, most of PhDs working in Brazil had their degrees abroad: Theology (76.4\% abroad), Aviation and Aerospace Engineering (70.5\%) and Computer Science (54.2\% abroad). International cooperation is often linked to the evolution of publication activity (Glänzel et al. 2006).

In Figure 1, our data shows the trend of PhDs graduated abroad in Computer Science reduced in 2011 to $35.1 \%$ among faculties affiliated to $\mathrm{PhD}$ programmes. This change is due to new policies for concession of $\mathrm{PhD}$ scholarships abroad aiming to reduce costs and to avoid problems related to migration of researchers to other countries (Ramos and Velho 2011).

Data from 2010 shows the evolution of postgraduate programs has played a key role to the growth of scientific knowledge in Brazil (de Almeida and Guimarães 2013). Mena-Chalco et al. (2012) evaluated the profile of the bibliographical productions of Brazilian programmes in Computer Science from 2004 to 2009. They highlighted the Brazilian computing area has a preference towards publishing in conference proceedings (approximately $71.5 \%$ being full papers, short papers and abstracts), followed by journals (approximately $15.9 \%$ ) and $12 \%$ of books, book chapters and others. Silva et al. (2017) also studied production and collaboration patterns of Brazilian CS programs. Another characteristics of Computer Science community is its high inequality of gender, with the prevalence of male researchers (Arruda et al. 2009). Interestingly, female researchers are more likely to have a higher-rank of productivity grant.

In this study, we characterize the trajectory of Computer Science researchers in Brazil, similarly to the work of Way et al. (2017) on the North American case. Although our data structurally differs from their work, we were able to draw comparisons between Brazilian and North American research systems. In our study we have taken into consideration the following important 


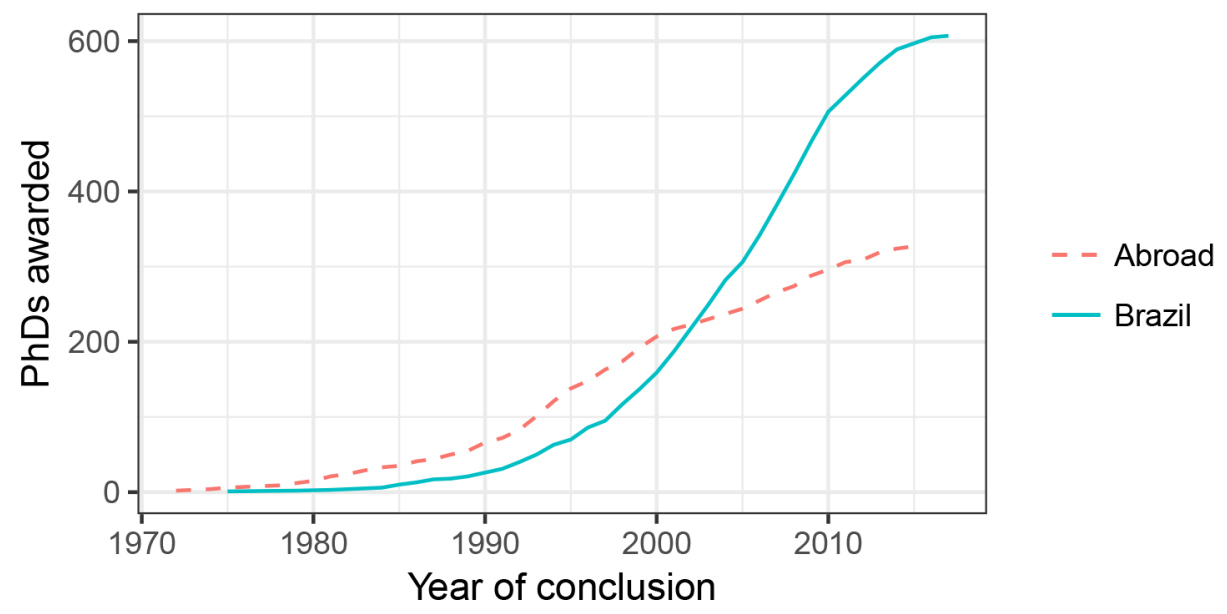

Figure 1 - Origin of $\mathrm{PhDs}$ for faculties working in Computer Science $\mathrm{PhD}$ programmes according to data from Brazilian Ministry of Education.

$$
\text { type } \rightarrow \text { all } \rightarrow \text { CS }
$$

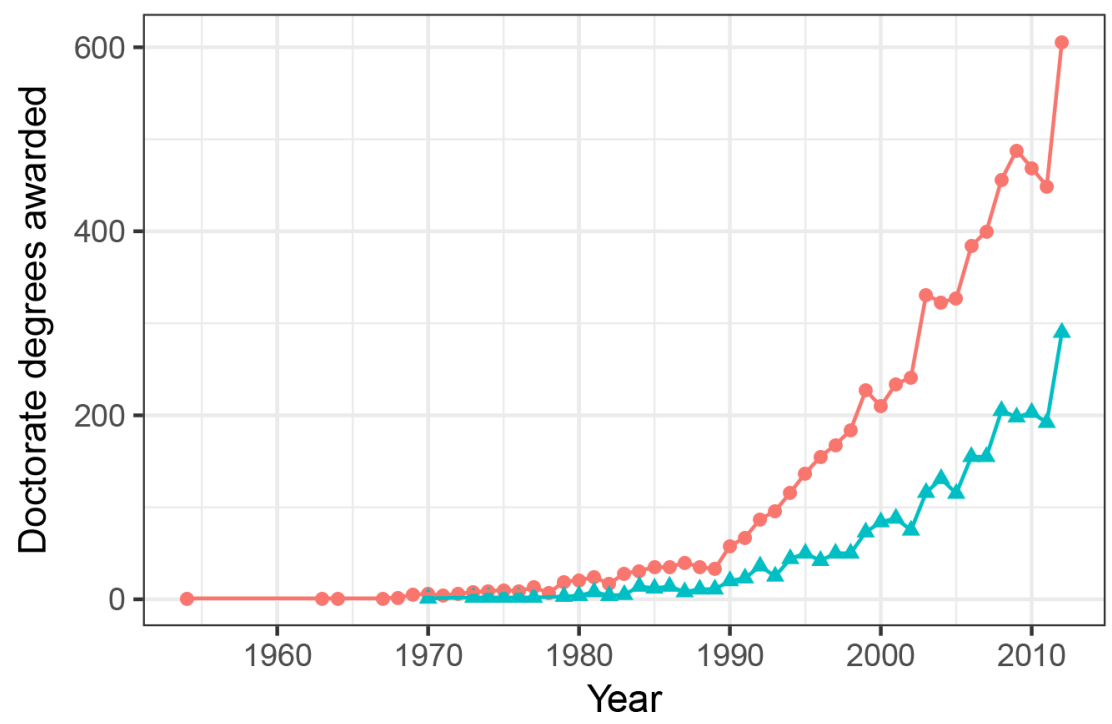

Figure 2 - Growth of number of doctorate degrees since the end of decade of 1980. Dots indicate number of doctorate degrees granted each year among those who declared to work in Computer Science. Curve labeled with "CS" indicates number of Computer Science degrees and "all" is unrestricted among those who work in the Computer Science field.

Brazilian characteristics: academic tenure probationary period of 3 years and tenure-track faculties are rarely denied tenure ${ }^{1}$; research usually

\footnotetext{
${ }^{1}$ This is distinct from US and Canada tenure in which the duration of tenure track and rate of approval can vary. Some reports states an average of 6 years to tenure be approved (Batterbury 2008). These distinction of tenure-track may
}

is performed in public institutions (Mugnaini et al. 2004, Mendes et al. 2010, Santos et al. 2012); only 5 among the 50 institutions with highest prestige are private ((Ranking Web of Universities 2017); and most of $\mathrm{PhDs}$ work in public institutions $(86 \%$

affect patterns of faculty productivity. 
according to data collected for this study — see Table II).

Another distinction between Brazilian and North American systems is that in order to advise a $\mathrm{PhD}$ student, a Brazilian tenured faculty often need to be accepted into, first, a Master Science and, later, a $\mathrm{PhD}$ programme. Each programme can establish its own acceptance guidelines. However, in a few places, this acceptance is automatic as soon as the faculty is hired and in others a researcher may need to wait at least 3 years in order to have succesfully advised undergraduate and master students.

The remaining sections of the paper are organized as follows: Section "Data" describes how we collected, structured and analysed our data on productivity and prestige of institutions. In Section "Publication Rates and Prestige", we evaluate overall productivity growth over time and study how productivity of early career of researchers and median publication count are related to prestige of institutions. Section "Analysis of Average and Individual Trajectories" presents a study of models of average and individual productivity of trajectories of at least 30 years of work. The final section draws conclusions about the current state of the Brazilian Computer Science community.

\section{DATA}

The Brazilian Ministry of Science, Technology and Inovation developed and maintains the Plataforma Lattes $^{2}$, a website used to store and publish academic resumes. Researchers must host their resumes in Plataforma Lattes to submit grant requests to Brazilian agencies. The study of the impact of Brazilian researchers often use Plataforma Lattes to compute productivity metrics, for example, total of production, total of citations, and h-index (Wainer and Vieira 2013, Leite et al. 2011).

\footnotetext{
${ }^{2}$ Plataforma Lattes: http://lattes.cnpq.br.
}

TABLE I

Summary of statistics about collected Curriculum Vitaes.

\begin{tabular}{lc}
\hline \multicolumn{1}{c}{ Profile } & Counting \\
\hline CV's (any type) stated to work in CS & 20655 \\
CV's (CS-only) affiliated to a top-200 & 7992 \\
institution & \\
PhDs (any type) working in CS & 6605 \\
PhDs (any type) affiliated to a top-200 & 4370 \\
institution & \\
PhDs (CS-only) working in CS & 2849 \\
$\begin{array}{l}\text { PhDs (CS-only) affiliated to a top-200 } \\
\text { institution working in CS }\end{array}$ & 2026 \\
\hline
\end{tabular}

TABLE II

Distribution of doctorates among type of institutions and prestige ranks. Percentage of PhDs refers to number of CV per institution, per rank.

\begin{tabular}{lccc}
\hline \multicolumn{1}{c}{ Rank } & CV's & Institutions & \% PhDs \\
\hline \multirow{3}{*}{$1^{\text {st }}-50^{\text {th }}$} & 410 & \multicolumn{3}{c}{ Private Institutions } \\
\cline { 2 - 4 } $51^{\text {th }}-100^{\text {th }}$ & 594 & 20 & 57.5 \\
$101^{\text {th }}-200^{\text {th }}$ & 320 & 59 & 46.8 \\
& \multicolumn{3}{|c}{ Public Institutions } \\
& \multicolumn{3}{|c}{45.3} \\
$1^{\text {st }}-5^{\text {0t }} \mathrm{h}$ & 5485 & 45 & 58.8 \\
$51^{\text {th }}-100^{\text {th }}$ & 823 & 30 & 50.3 \\
$101^{\text {th }}-200^{\text {th }}$ & 360 & 42 & 33.8 \\
\hline
\end{tabular}

We also accessed data from Sucupira System organized by the Ministry of Education, from which we identified who are the current faculties in Computer Science doctorate programmes ${ }^{3}$.

Way et al. (2017) used data for the 20112012 academic year from faculties given three restrictions: they work in one of the 205 North American PhD programmes; they obtained their PhDs in North America; and they got their first assistant professorship in one of these institutions. Therefore, they selected 2583 faculties in their study.

In Brazil, for the 2018 academic year, there were $31 \mathrm{PhD}$ programmes in Computer Science,

\footnotetext{
${ }^{3}$ Available at https://sucupira.capes.gov.br . Date of Access: March, 13th 2018.
} 
in which 1072 faculties were affiliated as regular members. However, we have identified only 181 among all 1072 faculties adhere to those same three conditions chosen by Way et al. (2017). Still, only 90 of them have a career of at least 10 years, which is a condition used by Way et al. (2017) to estimate their piecewise model parameters.

Another peculiarity of the work by Way et al. (2017) is their usage of a hiring-based prestige previously introduced by Clauset et al. (2015). The hiring-based prestige is related to the proportion of doctorates from a institution to be hired as professor in a high-prestige institution. For the Brazilian case, considering faculties hired by first time up to 2012, we found only 12 institutions whose PhDs were awarded and hired by the $31 \mathrm{PhD}$ programmes available in 2018 .

Therefore, due to the low number of faculties and $\mathrm{PhD}$ programmes, instead of reproducing exactly the same analysis of Way et al. (2017) paper, we extended our data to any person with resume stored in Plataforma Lattes who declared Computer Science to be a subject of interest $(N=20655)$. Consequently, we could not replicate all details of their analysis. One important difference is the definition of length of career, which we defined as the number of years from the first academic publication, whereas Way et al. (2017) defined as number of years from the first hiring as professor in a university.

The methodology of data collection followed a breadth-first traversing of the graph of collaborators declared by researchers in their curriculum vitae and used the resumes of faculties of some computer science departments in Brazil as starting vertices. Researchers affiliated to the following institutions were used: Universidade de São Paulo, Universidade Federal de Juiz de Fora, Universidade Federal de Lavras, Universidade Federal de Minas Gerais, Universidade Federal de São João del-Rei, Universidade Federal de Uberlândia, Universidade Federal de Viçosa,
Universidade de Campinas, Universidade Federal de Alfenas, Universidade Federal de Itajubá. While this list is not comprehensive, we found a graph component with 564495 vertices from which we selected $N=20655$ resumes who declared to work in the field of "Computer Science" (CS) which also updated CV information from 2012 onwards. The algorithm of breadth-first traversing stopped when no new collaborators were found. This collecting process took place from mid-2013 up to early 2014, when Plataforma Lattes introduced a captcha system to avoid automatic data retrieval. We used GNU/Linux scripting tools to download (wget) curriculum vitaes' pages and customized code to parse and look for links of collaborators' pages.

In Plataforma Lattes, each person declares a list of fields in which his activities are better represented and links the resumes of the main collaborators. Note there is no data about which field is their main one. Table I presents statistics regarding the profiles of resumes considered in this paper. In this table, $\mathrm{PhD}$ students are also included.

In the collected data there are: full name, affiliation details, fields of activity, and bibliographic data on papers, books, chapters and other publication items. In this paper, except when otherwise stated, we only counted as publications the following items: papers in journals, books, chapters and full papers in proceedings. All publications date from 1956 to 2012 .

Note that, differently from data used by Way et al. (2017), these 20655 researchers are not only faculties as they can also be technicians and students. Therefore, we have analyzed publication records using the year of first publication which can differ from the year of first hire.

There is also data on academic degrees and year of conclusion of $\mathrm{PhD}$ with its title (e.g. Doctor of Science, Dr. rer. nat., PhD in Computer Science, and PhD Electric Engineering). From those who declared to work in Computer Science, we have found 6605 doctorates. From those, 2849 
have earned a doctorate degree title with words containing prefixes of "comput" or "inform" stems. Throughout this paper, we used this method to identify Computer Science (CS) degrees.

The curve of the years of conclusion of PhDs is shown in Figure 2. In this figure, the curve labeled with "all" includes all types of degrees and the curve "CS" refers the counting of Computer Science PhDs. These curves show the CS research in Brazil has begun its growth during the decade of 1980 .

Due to the lack of data for computing a prestige ranking based on hiring following methodology of Clauset et al. (2015), instead we used the list of 200 best-ranked academic institutions according to Webometrics Ranking of World Universities ${ }^{4}$. The Webometrics ranking uses indicators based on link analysis of institutional web pages and bibliographic citation analysis. Combining data from Plataforma Lattes and the Webometrics Ranking, we have identified 7992 researchers working in Computer Science in the 200 bestranked institutions in Brazil.

There are differences in productivity due to prestige. We have stratified institutions into three rank levels: level 1 - from 1st to 50th, level 2 rank 51st to 100th, and third level -101 st to 200th. Table II shows distribution of doctorates according to the prestige groups and type of institutions. This distribution is important to characterize the role of public and private institutions in research. The number of doctorates decreases according to prestige level. Also, the proportion of doctorates in public institutions is higher than private institutions. In Figure 3, the average publication counts perperson in institutions in each level are shown.

Among all Brazilian institutions considered, only one institution is among the world top 200: Universidade de São Paulo (world rank 63). The

\footnotetext{
${ }^{4}$ Ranking available at http://www.webometrics.info/en/ Latin_America/Brazil.
}

number of doctorates affiliated to Universidade de São Paulo is 685.

As argued by Way et al. (2017), it would be misleading to compare a 1960 publication with a 2012 publication as the rate of production has increased with time. This phenomena is also noticed in Figure 4. In the following analysis, publication counts are reported as taking 2012 as year of reference using the same equations as economists use to compute the value of the dollar of 1960 in 2012. For each year $Y$, its inflation $r(Y)$ is calculated using $\bar{c}(2012)$, the average publication count per person in 2012, and the corresponding average counting $\bar{c}(Y)$ of year $Y$ according to Equation 1. Figure 3 shows average publication rates per-person not adjusted to inflation, according to prestige ranks. As mentioned by (Arruda et al. 2009, Cabanac et al. 2015, Cavero et al. 2014), counting the total of publications can suffer from overcounting as a publication is counted as many times as the number of authors. This affects Figures 3 and 4. However, this overcounting effect is attenuated in our analysis of individual trajectories by the inflation correction.

$$
r(Y)=\frac{c(2012)-\bar{c}(Y)}{\bar{c}(Y)}+1
$$

In addition, in 2001, Guimarães et al. (2010) found out just over half of Brazilian Computer Science researchers trained abroad. By comparison, the majority of North American faculty is trained in North American and originate from a small number of prestigious universities, while in Brazil 34.9, $65 \%$ of faculties in $\mathrm{PhD}$ programmes is graduated abroad.

Although the number of $\mathrm{PhDs}$ concluded abroad has reduced, we found there are still differences between these two classes. For example, considering the CNPq productivity grant distribution among researchers affiliated to graduate programmes, the proportion of those 

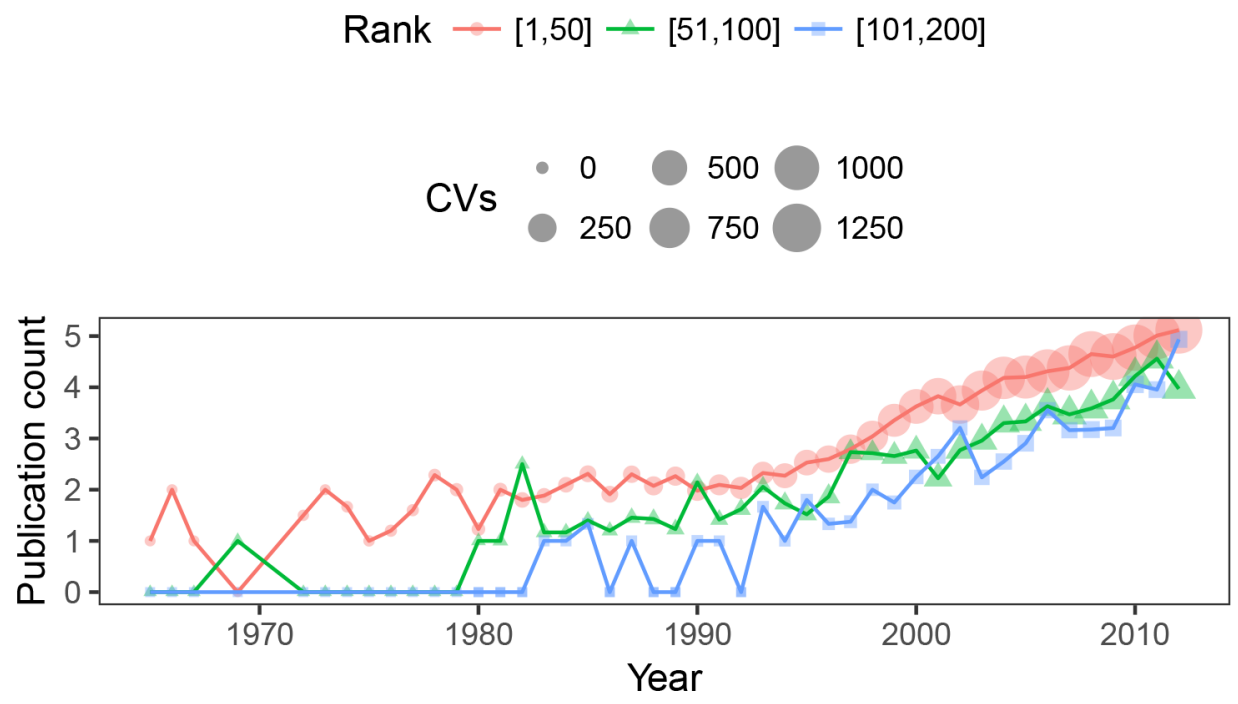

Figure 3 - Average publication rate per-researcher according to the prestige rank of their institutions. This figure counts publications in CVs of researchers with $\mathrm{PhD}$ in Computer Science which declared affiliation to a top-200 institution. This rate increases around 1995 due to the growth of the number of $\mathrm{PhDs}$

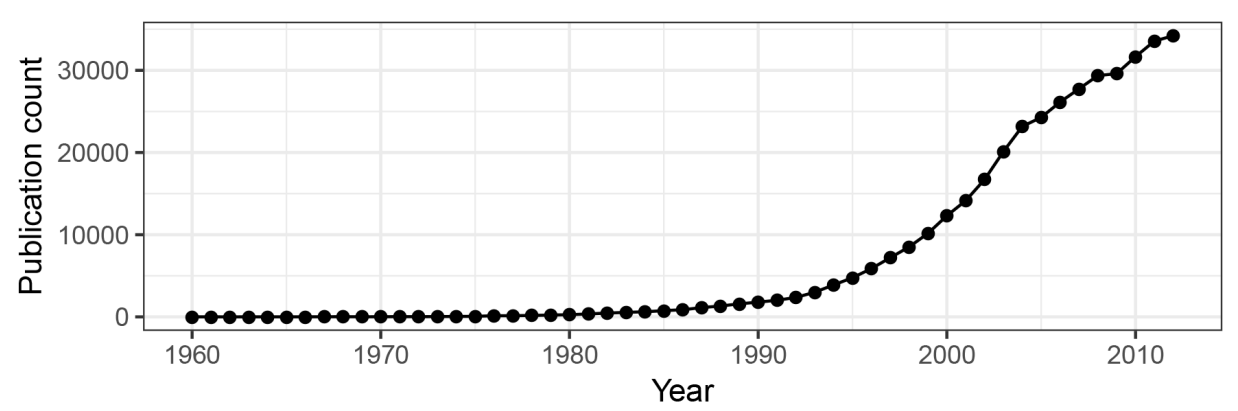

Figure 4 - Total number of publications by those who declared to work in Computer Science. This counting considers books, book chapters, articles in journal and publications (articles, extended abstracts, and abstracts) in conference proceedings.

graduated abroad with a grant is $45 \%$, while for those graduated in Brazil is $35.4 \%$.

Therefore, researchers graduated abroad are more likely to obtain a higher category productivity grant than those graduated in Brazil.

\section{PUBLICATION RATES AND PRESTIGE}

The Brazilian Computer Science research community has begun to grow during the decade of 1980, when the number of PhDs has increased (Figure 2). This growth, seen in other fields (de Meis et al. 2007), also affects the number of publications each year, shown in Figure 4. From 1980 to 2000, the publication count approximately doubles every 4.5 years. This rate of growth changed around 2004, when publication counts grew only linearly. This is highlighted by the fact that from 2001 to 2004 (4 years), the publication count increased $58 \%$ (9677 more publications), while from 2004 to 2012 (9 years), it increased only 31\% (8183 more publications).

Previous studies have found that researchers from more prestigious institutions tend to be more productive. Way et al. (2017) found the faculty in the 50-highest prestige institutions in North 
America have, in average, 30\% higher production rate per-person than those in positions 101 to 200. In our case, the institutions in first level of prestige ranks have production $38.36 \%$ higher than those in the second level and $73.7 \%$ higher than the institutions in positions 101 to 200 .

Figure 5 shows median publication counts of doctorates correlated with institution prestige. Our data corroborates this finding as indicated by positive slopes of 0.19 for public and 0.06 for private institutions.

The type of institution is relevant to productivity analysis as among the 50 most prestigious Brazilian institutions only 5 are private. This contrasts with the scenario in North America, where the number of institutions in the highest prestige level is about $50 \%$ for each of the types. Additionally, among the institutions with the 50-highest median count only 11 are private.

There are 35 institutions in the highest level among the 50 institutions with the highest median count, while 13 institutions with highest median are in the 51-100 prestige level.

Way et al. (2017) have identified for North American institutions that publication counts over the early career correlate with prestige but not with the type of institution. In Brazil, we have identified a weak correlation of publication counts with prestige and also with the type of institution.

However, this observation changes when considering productivity over entire careers of $\mathrm{PhD}$ holders as seen in Figure 5. In this case, the regressions show a stronger correlation of median publication counts with prestige for public institutions

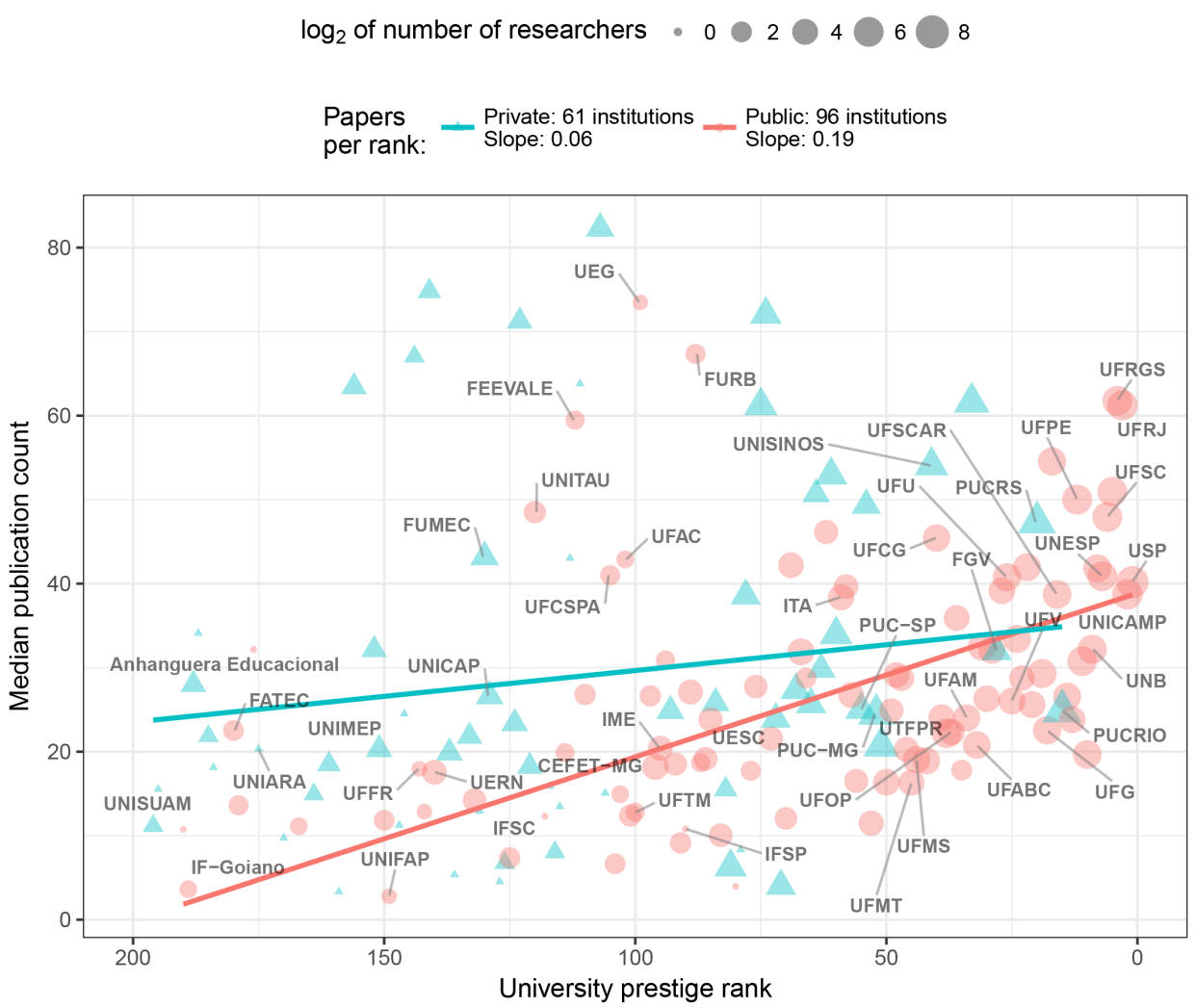

Figure 5 - Median publication count of doctorates correlated with institution prestige. Points indicate the median number of publications adjusted for inflation. Lines are robust linear regressions (Venables and Ripley 2002) weighted by the number of researchers in each institution. This kind of linear regressions provided by package MASS in R project is used to avoid outliers and follow tendencies according to the number of researchers in each institution. 
(slope equals to 0.19 ) than private ones (slope equals to 0.06 ). Among the researchers who do not hold a $\mathrm{PhD}$ degree, the median publication count does not correlate with prestige nor type of institution.

\section{ANALYSIS OF AVERAGE AND INDIVIDUAL TRAJECTORIES}

Figure 6 shows the trajectories of careers in top-50 institutions follow the conventional peak-decline pattern. Although less individual trajectories are available, this type of pattern seems also to be present for senior researchers with longer careers.

On the other hand, in the analysis of individual trajectories, we find a higher variability of productivity patterns. Figure 7 shows a concentration of peaks of productivity around the 10th year of career among the 1000 most productive researchers. This is similar to the tendency shown by Way et al. (2017) for the North American case, although the average of most productive year in our case is shifted by about 5 years. We attribute this difference to our definition of the length of career.

Way et al. (2017) characterized the productivity pattern within an individual career as a piecewise model, which is presented in Equation 2. The piecewise model uses two linear functions with slope coefficients $m_{1}$ and $m_{2}$ and a point of change $t^{*}$ used by an indicator function $I\left(t>t^{*}\right)$, and $b_{1}$ is the initial productivity.

$$
f(t)=b_{1}+m_{1} t+m_{2}\left(t-t^{*}\right) \cdot I\left(t>t^{*}\right)
$$

In order to understand the publication trajectories of senior researchers, we have also included polynomials of higher degrees (linear, quadratic, cubic, up to 6th degree) in our pool of models.

Figure 8 presents a visualization of trajectories using $m_{1}$ and $m_{2}$ coefficients from Equation 2. In this figure, trajectories are marked by symbols (circle, triangle, square, plus sign, and crossed square) which identify the best-matching model according to the Bayesian Information Criterion (BIC) (Schwarz 1978). This criterion is useful to penalize overly-complex models.

Each trajectory is fitted using all models, which are the piecewise-linear model and the polynomials where degree 1 up to 6 , and compared with the $\mathrm{BIC}$ values. If the best $\mathrm{BIC}$ value of a model for a trajectory is a polynomial with degree 4 or higher, it is marked as unstable.

$$
\text { Rank } \simeq[1,50] \simeq[51,100]=[101,200]
$$

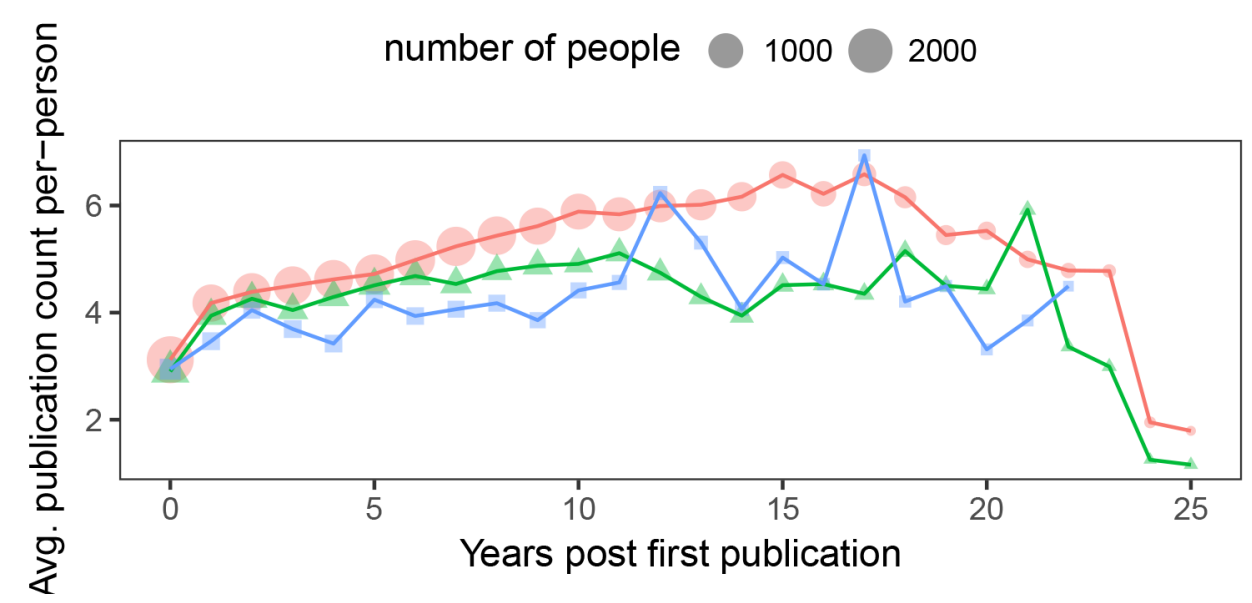

Figure 6 - Average trajectories of researchers in top 50 institutions with career length of 10 to 25 years follow a peak-decline shape. 


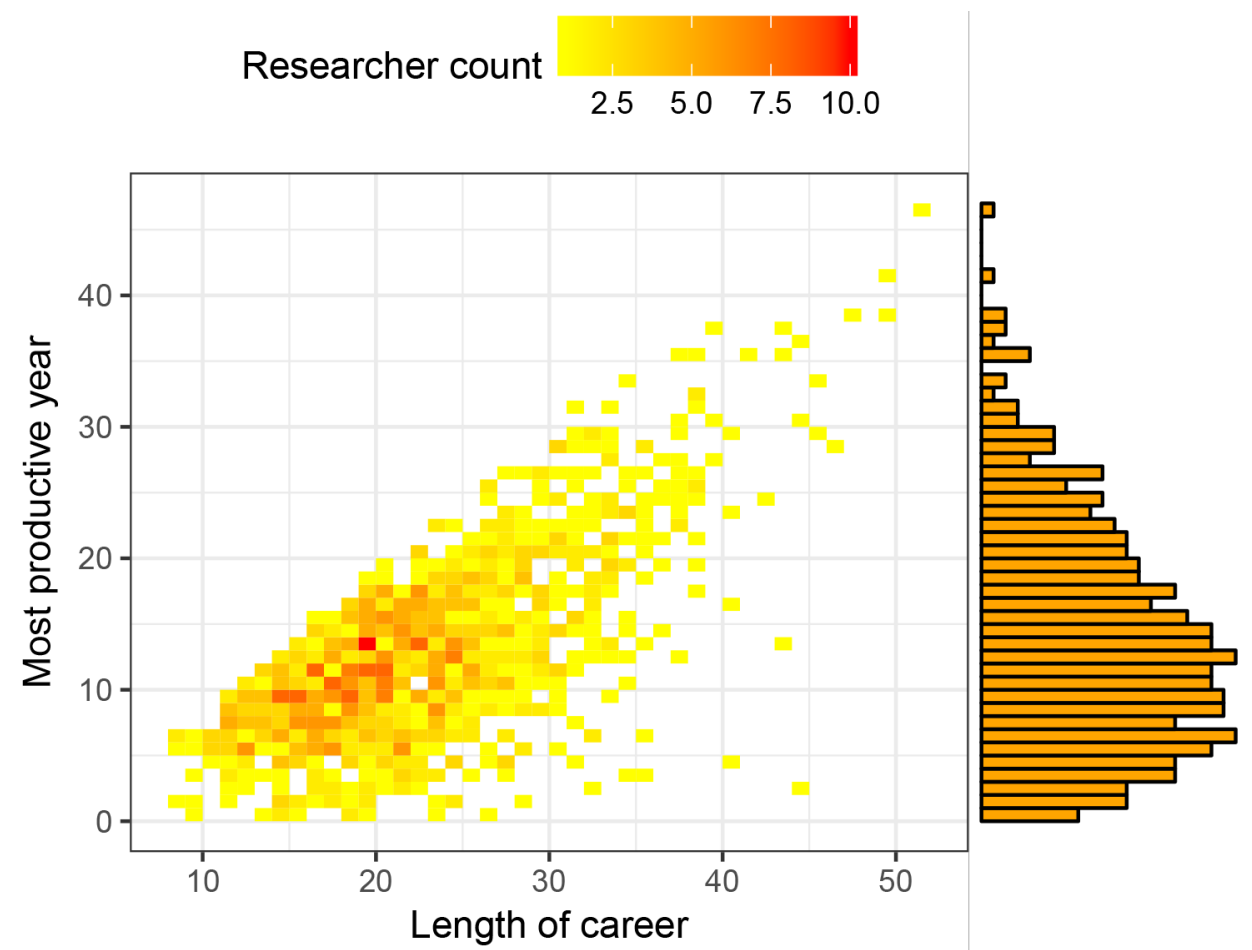

Figure 7 - Heat map of the peak-year for the 1000-most productive researchers in the Brazilian Computer Science community.



Figure 8 - Visualization of trajectories using coefficients of a piecewise linear function for career trajectories of senior researchers (288 trajectories). Each trajectory is marked by the best-fitting model according to BIC value. The piecewise-linear function had the smallest BIC for 58 (20.1\%) trajectories. Only $C N=70$ are within the octant corresponding to the conventional narrative, that is $m_{1}>0, m_{2}<0$, and $m_{1}>\left|m_{2}\right|$. Among the trajectories in $C N$, only $4.5 \%(N=13)$ are best-fit with piece-wise model. The number of trajectories in the quadrants are $\mathrm{Q} 1=15, \mathrm{Q} 2=77, \mathrm{Q} 3=33$, and $\mathrm{Q} 4=163$. 
The quadrants Q1, Q2, Q3 and Q4 allow checking how the trajectories are evolving according to the piecewise model. The shadowed area, an octant indicated by $C N$, implies a starting positive slope followed by a decreasing slope which represents the conventional narrative of the academic trajectories: a rapid-rise and gradual-decline pattern.

In the study of the trajectories, we have found the linear model best fits the largest number of trajectories (91 trajectories). The piecewise linear model is the second most common with 58 trajectories. However, the number of unstable trajectories is significant (65 trajectories).

In Way et al. (2017) work, they have identified $44.9 \%$ of trajectories as linear and $20.3 \%$ as following the conventional narrative. In our data, only $31.5 \%$ are linear and $4.5 \%$ are conventional narrative.

\section{RESEARCH IMBALANCE}

Individual trajectories can be affected by factors linked to the years during which researchers started their careers (Way et al. 2017). For example, Way et al. (2017) observed that faculties among those first hired during the $1970 \mathrm{~s}$, $50 \%$ of academic publications of their 5 first years were produced by the $15 \%$ most productive.

In our data collected from the Brazilian CS community, taking into account the inflation correction of publication counts, we have found a weak correlation between production imbalance with seniority. The Gini's index for productivity among researchers who started their careers before 1980 s is $G=0.44$. For the 1980 s, the imbalance increased to 0.47 , and, for the 1990 s lowered to 0.46 and, for the 2000 s, the imbalance increased to $G=0.48$.

The imbalance of $2000 \mathrm{~s}$ indicates approximately $50 \%$ of the production among those researchers is attributed to the $20 \%$ most productive. Although these indexes over time represent a small increase in imbalance, it may indicate a tendency of concentration of publications among fewer researchers. We believe further data is needed to understand this tendency, which could be explained by several factors, among those: competition among senior and junior researchers for grants and students; and overhead for young researchers who started their careers in institutions in process of development.

\section{CONCLUSIONS}

In this paper, we evaluated characteristics of the Brazilian Computer Science community. Using data from Ministério daEducação and Ministério da Ciência e Tecnologia, we found 20655 active researchers from which about $38.7 \%$ are $\mathrm{PhDs}$ affiliated to one of the 200 best-ranked Brazilian institution.

We found only $43.1 \%$ of PhDs awarded with a title specific to Computer/Information Sciences. The number of Brazilian CS PhDs has begun to grow around 1995 which has also accelerated the publication in the area. However, only in 2001 institutions has begun hiring more $\mathrm{PhDs}$ graduated in Brazil than those graduated abroad. We noticed one important distinction as $\mathrm{PhDs}$ with titles awarded abroad (45\%) are more likely to receive $\mathrm{CNPq}$ productivity grants than $\mathrm{PhDs}$ titles awarded in Brazil (35.4\%).

Although Brazilian government has invested in development of universities, CS academic community in Brazil is still underdeveloped. According to 2018 data, there are only 31 Brazilian $\mathrm{PhD}$ programmes in comparison to 205 programmes in North America. More specifically, according to data from the last official report regarding graduate programmes, only $12 \mathrm{PhD}$ programmes have trained researchers which were hired among the current 31 programmes.

Publication rate growth have followed $\mathrm{PhD}$ conclusion rise in Brazil until 2005. We found that the median production count is correlated with prestige and also with the type of institution (private or public). A counterintuitive fact discovered is that researchers in their early career have higher 
production median in private institution than in public ones.

Similarly to Way et al. (2017) study, we found individual researcher trajectories often do not follow rapid-rise, short-peak gradual decline pattern. Less than $5 \%$ of careers can be described by the conventional narrative.

\section{AUTHOR CONTRIBUTIONS}

MKA and ALS collected the data and created the figures. ARB and MKA performed data analysis and wrote the paper. All authors contributed toward interpreting the results, revising, and improving the paper.

\section{REFERENCES}

ARRUDA D, BEZERRA F, NERIS VA, ROCHA DE TORO P AND WAINERA J. 2009. Brazilian computer science research: Gender and regional distributions. Scientometrics 79(3): 651-665.

BATTERBURY S. 2008. Tenure or permanent contracts in North American higher education? A critical assessment. Policy Futures in Education 6(3): 286-297.

BAYER AE AND DUTTON JE. 1977. Career age and researchprofessional activities of academic scientists: Tests of alternative nonlinear models and some implications for higher education faculty policies. J of High Educ 48(3): 259-282.

CABANAC G, HUBERT G AND MILARD B. 2015. Academic careers in computer science: continuance and transience of lifetime co-authorships. Scientometrics 102(1): 135-150.

CAÑIBANO C AND BOZEMAN B. 2009. Curriculum vitae method in science policy and research evaluation: the stateof-the-art. Res Evaluat 18(2): 86-94.

CAVERO JM, VELA B AND CÁCERES P. 2014. Computer science research: more production, less productivity. Scientometrics 98(3): 2103-2111.

CLAUSET A, ARBESMAN S AND LARREMORE DB. 2015. Systematic inequality and hierarchy in faculty hiring networks. Sci Adv 1(1).

DE ALMEIDA ECE AND GUIMARÃES JA. 2013. Brazil's growing production of scientific articles-how are we doing with review articles and other qualitative indicators? Scientometrics 97(2): 287-315.

DE MEIS L, ARRUDA AP AND GUIMARÃES J. 2007. The impact of science in Brazil. IUBMB Life 59(4-5): 227-234.

FORTUNATO S, BERGSTROM CT, BÖRNER K, EVANS JA, HELBING D, MILOJEVIC S AND BARABÁSI AL. 2018. Science of science. Science 359(6379).

GLÄNZEL W, LETA J AND THIJS B. 2006. Science in Brazil. part 1: A macro-level comparative study. Scientometrics 67(1): 67-86.
GUIMARÃES R, LOURENÇO R AND COSAC S. 2010. O perfil dos doutores ativos em pesquisa no Brasil. Parcerias Estratég 6(13): 122-150.

LEITE P, MUGNAINI R AND LETA J. 2011. A new indicator for international visibility: exploring Brazilian scientific community. Scientometrics 88(1): 311.

LEVIN SG AND STEPHAN PE. 1991. Research productivity over the life cycle: Evidence for academic scientists. Am Econ Rev 81(1): 114-132.

MENA-CHALCO JP, DIGIAMPIETRI LA AND OLIVEIRA LB. 2012. Perfil de produção bibliográfica dos programas brasileiros de pós-graduação em ciência da computação. Encontro Brasileiro de Bibliometria e Cientometria 3.

MENDES PHC, MARTELLI DRB, SOUZA WPD, QUIRINO FILHO S AND MARTELLI JÚNIOR H. 2010. Perfil dos pesquisadores bolsistas de produtividade científica em medicina no CNPq, Brasil. Rev Bras Educ Méd 34(4): 535-541.

MUGNAINI R, JANNUZZI PDM AND QUONIAM L. 2004. Indicadores bibliométricos da produção científica brasileira: uma análise a partir da base Pascal. Ciênc Info 33(2): 123-131.

PICININ CT, PILATTI LA, KOVALESKI JL, GRAEML AR AND PEDROSO B. 2016. Comparison of performance of researchers recipients of cnpq productivity grants in the field of Brazilian production engineering. Scientometrics 109(2): 855-870.

RAMOS MY AND VELHO L. 2011. Formação de doutores no Brasil e no exterior: impactos na propensão a migrar. Educ Soc 32: 933-951.

RANKING WEB OF UNIVERSITIES. 2017. Ranking web of universities. https://www.webometrics.info/en/detalles/ usp.br

SANTOS MIP, LEITE BGL, PARANAÍBA LMR, OLIVEIRA EA, VERÍSSIMO FM, OLIVEIRA RADD AND MARTELLI-JÚNIOR H. 2012. Profile and scientific production of Brazilian researchers in oral pathology. Revi Odontol UNESP 41(6): 390-395.

SCARPELLI AC, SARDENBERG F, GOURSAND D, PAIVA SM AND PORDEUS IA. 2008. Academic trajectories of dental researchers receiving CNPq's productivity grants. Braz Dent J 19(3): 252-256.

SCHWARZ G. 1978. Estimating the dimension of a model. Ann Stat 6(2): 461-464.

SILVA THP, LAENDER AHF, DAVIS CA, DA SILVA APC AND MORO MM. 2017. A profile analysis of the top Brazilian computer science graduate programs. Scientometrics 113(1): 237-255.

VENABLES WN AND RIPLEY BD. 2002. Modern applied statistics with S (Fourth ed.). New York: Springer.

WAINER J AND VIEIRA P. 2013. Correlations between bibliometrics and peer evaluation for all disciplines: the evaluation of Brazilian scientists. Scientometrics 96(2): 395-410.

WAY SF, MORGAN AC, CLAUSET A AND LARREMORE DB. 2017. The misleading narrative of the canonical faculty productivity trajectory. Proceedings of the National Academy of Sciences of the United States of America 1-8. 